\title{
A Study of Traditional Toy Making in Channapatna, and Proposal of an Artisan Village
}

\author{
Ar. Uma S M, B. Shankar, Aparna Agaram Krishnan
}

\begin{abstract}
Toys are objects made for a child to play with and explore their surroundings. Toys aid in the physical, emotional, cognitive and social development of children. Channapatna toys are soft-wood toys that are made in Channapatna, about $60 \mathrm{~km}$ southwest of Bangalore. The toys are eco-friendly, non-toxic and child safe and have been recognized as GI tagged commodities. Artisans majorly acquire the skills from their families who are into toy making since generations, or from a master craftsmen who acts as a head of a group of artisans. It is a craft that is passed on from generation to generation. The toys are also exported and have buyers in an international market. In this research paper, the process of traditional toy making, raw materials required, and methods have been studied in detail, along with the challenges faced by artisans. The artisans engaged in the craft form are mostly dependent on middle-men, and are unaware of benefits and facilities that are available. The paper briefly outlines possible architectural interventions that can improve the working conditions of artisans, and preserve the traditional craft form.
\end{abstract}

Key words: Craft-cluster, eco-friendly toys, lathe turned wooden toys, traditional toy making

\section{INTRODUCTION}

Situated about $60 \mathrm{~km}$ southwest of Bangalore, there is a town called Channapatna, locally known as 'Gombegala Ooru' (Toy town). Channapatna is a taluk headquarter in Ramanagara district, Karnataka. It is said King Tipu Sultan who ruled from 1750 to 1799, received a lacquered Persian toy which excited him enough to send for artisans from Persia to train the local artisans to make similar toys. The Indian artisans settled in Channapatna, about $55 \mathrm{~km}$ from Tipu Sultan's capital Srirangapatna, and have continued practicing the same craft through generations. It is believed that Tipu Sultan encouraged the use of mechanized lathes to carve the toys, and helped the artisans to procure mechanized lathes to produce toys. (Shrivatsava, 2016) The Channapatna city Municipal Council has a population of 71,942 amongst which 36098 are male and 35,844 are female. Around $60 \%$ of the population are engaged in some form of artistry. The female sex ratio (993) is higher than the state average (973). The literacy rate is $84.7 \%$. Male literacy rate $(88.13 \%)$ is slightly higher than female literacy rate (81.28\%).

Manuscript received on September 20, 2021.

Revised Manuscript received on November 20, 2021.

Manuscript published on November 30, 2021.

* Correspondence Author

Ar. Uma S.M*, Assistant Professor, Department of Architecture, School of Planning and Architecture, University of Mysore (Karnataka) India.

Dr. B. Shankar, Reader Urban and Regional Planning, Institute of Development Studies, University of Mysore (Karnataka) India.

Aparna Agaram Krishnan, Bachelor Architecture School of Planning and Architecture, University of Mysore (Karnataka) India.

(c) The Authors. Published by Blue Eyes Intelligence Engineering and Sciences Publication (BEIESP). This is an open access article under the CC BY-NC-ND license (http://creativecommons.org/licenses/by-nc-nd/4.0/) (census.gov.in, 2021) About 4000 artisans work out of 250 homes and 50 small manufacturing units. In many cases, the components of toys are produced at one place, and assembled in another place. The types of artisans include freelancers, and those employed in registered toy making units. An artisan earns Rs 250 to Rs 400 a day, depending on their skill level, experience, and the number of hours they work per day. The pay scale of an artisan is meagre, and is in-sufficient to meet the demands of a family, dependent on a sole wage earner. Lakshmi has been making toys since she was 15 . Twenty five years later, she's an expert, having learnt and mastered the art from her mother. Her earnings are in-sufficient to meet her daily needs with, but she loves making toys. "I barely make Rs 300 a day, " says the mother of two. Lakshmi's older son, Suresh was a toy maker until three years ago, when he migrated to Bangalore in search of a better paying job. Suresh works in an electronics shop and makes Rs 11000 a month, more than three times what he used to earn making toys in Channapatna. Suresh is interested in preserving the traditional craft form, but adds that he cannot depend on practicing the craft from, as he has to support his family. With more and more toymakers giving up the profession and migrating to cities and other towns in search of a livelihood, today, the traditional craft form is dying. The photographs below show artisan Lakshmi at work carving toys, along with an apprentice, and artisans carving toys at a small scale toy making unit.
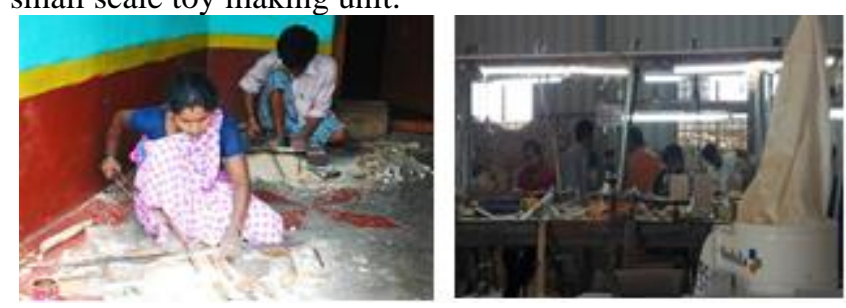

Figure 1 Artisans at work making toys

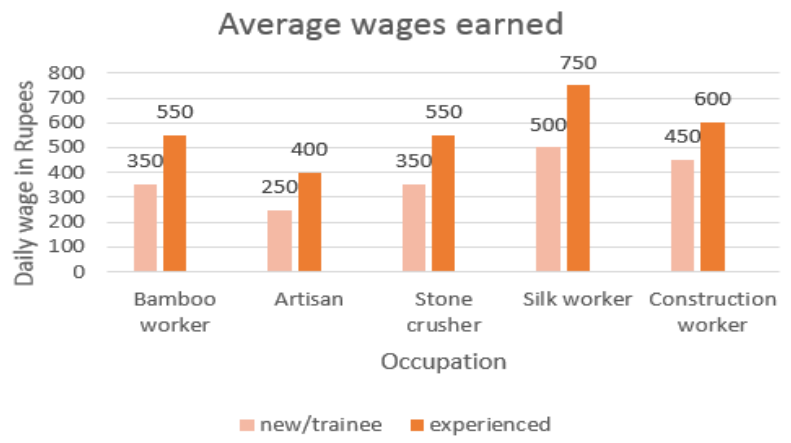

Figure 2 Bar Graph Showing Average Daily Wages Earned

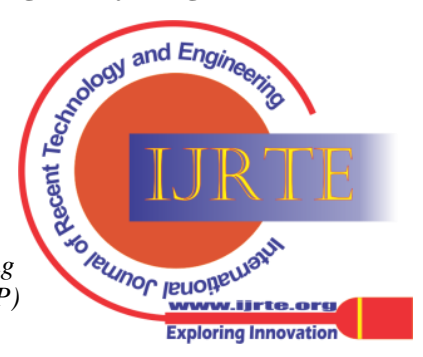




\section{A Study of Traditional Toy Making in Channapatna, and Proposal of an Artisan Village}

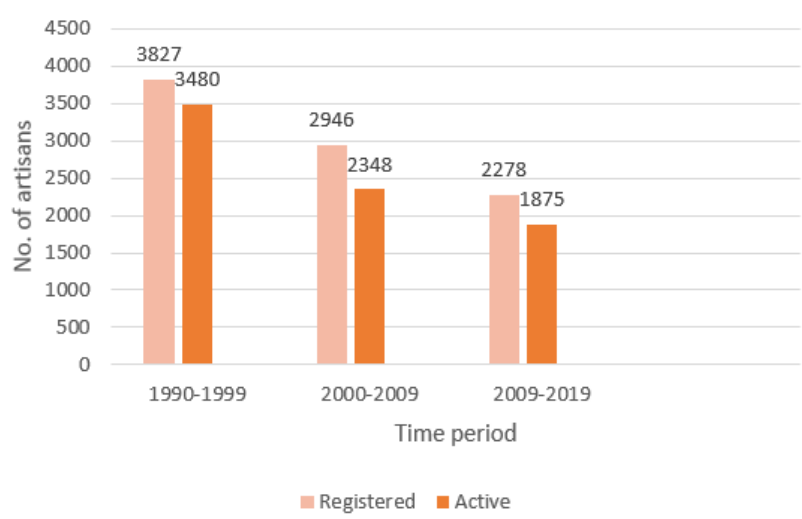

Figure 3 bar graph showing decline in the number of artisans practising the craft form

The average wages earned by an artisan is lower than the wages earned by workers engaged in silk, bamboo and construction work. This is one of the main reasons, for the fall in the number of artisans who practice the craft form.

The bar graph, shown in figure 3 shows the number of artisans registered with Karnataka Handicrafts Development Corporation (KHDC). The number of registered and active artisans has fallen steeply over the years.

Market research reports suggest that the demand for eco-friendly wooden toys is rising across the globe. More number of educators, and parents are aware of the hazardous nature of plastic, and its harmful impact on health of children, and the environment. Toys containing Bisphenol A, PVC, and plasticizers including adipates and phthalates as constituents are not suitable for kids and can have serious adverse effect on their health. Regulatory authorities in many countries including India, Germany, and Sweden have imposed ban on the use of these materials in toys. (www.grandviewresearch.com, 2021)

This acts as an opportunity to improve the production and sales of wooden toys. Wooden toys market in India which constitutes a minor market share in overall toys market, is expected to grow at a Compound annual growth rate (CAGR) rate of $25 \%$ in the next 5 years. (https://www.reportlinker.com/p03812874/Toys-Market-in-I ndia.html, 2021)

\section{RAW MATERIALS REQUIRED}

Artisans practicing the art form were interviewed verbally to know about the raw materials needed to make Channapatna toys. The raw materials required for the production of toys include ivory wood, lac, and leaves of the screw pine tree. Synthetic raw materials include paints, and pigments.

\section{A. Wood}

This tradition of toy making initially started with locally available 'Hale mara' (ivory wood), shown in Fig 4. The biological name of this tree is Wrightia tinctoria. The ivory wood tree grows in farmlands, forests and village waste-lands within a $100 \mathrm{~km}$ radius of Channapatna, and has a high pollination rate, making the craft self-sustainable. The tree grows in abundance in Maddur district, and the wood is distributed to the toy makers by the forest department.

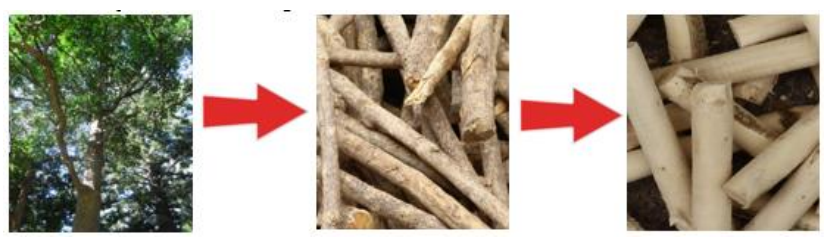

Figure 4 Ivory Wood Tree, Cut Logs, And Processed Logs.

The wood of the ivory tree is close grained, moderately hard, and can be carved by hand or machine. The wood has to be seasoned before production. Seasoning can be done by chemical methods, or by natural drying of the wood by sun-shine. Twenty six artisans, out of thirty preferred air drying over chemical methods, as shown in Fig 5.

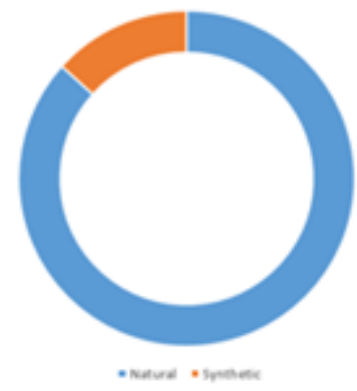

Seasoning time for a 1 inch by 1 inch block is about three months, while seasoning time of a 3 inch block is about five months.

Wood is cut into billets and seasoned until moisture content is reduced.

Figure 5 Pie Chart Showing Preference Of Artisans Of Drying Methods.

Ivory wood is preferred by the artisans, however silver oak, redwood, and rose wood are also used to make toys. Wood drying and seasoning are carried out in close proximity to wood workshops.

Table 1 Types of Wood used in toy making

\begin{tabular}{|l|c|l|}
\hline Type of wood & Percentage & Remarks \\
\hline Ivory wood & 91 & Most preferred \\
\hline Silver oak & 6 & $\begin{array}{l}\text { Used to make short } \\
\text { life span toys, not } \\
\text { long lasting }\end{array}$ \\
\hline Rose wood & 3 & $\begin{array}{l}\text { Used for specific, } \\
\text { custom made orders }\end{array}$ \\
\hline
\end{tabular}

Ivory wood is preferred as it is non-toxic, soft, and long lasting.

\section{B. Lac}

Lac is a deposit produced by an insect; Tachadria lacca. It is usually found on the barks of timber trees in forested regions. In the time of Tipu Sultan's reign, lac was naturally found in the forests near Channapatna. Now, however lac is purchased from other states, such as Tamil Nadu. The preparation of lacquer ware from lac begins with heating lac stuck on a wooden stick until the lac becomes malleable. A small measured amount of lithophone is added to the softened lac, and mixed until a white tint appears. Natural dye is then added to the mixture, and mixed until the desired tint is obtained as shown.

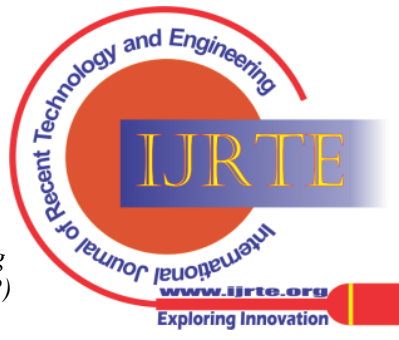


The lac's texture becomes like rubber and is then drawn into sticks that are $15-20 \mathrm{~cm}$ long, and $0.5 \mathrm{~cm}$ thick, as shown in figure 6 . These sticks have a shelf life of about 30 days.
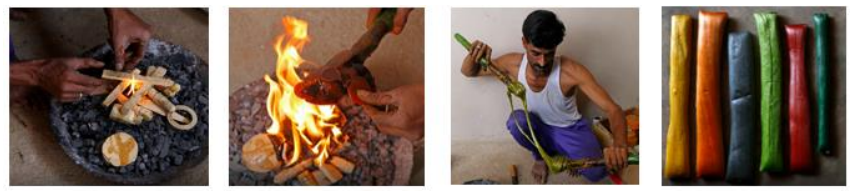

Figure 6 Colour making process

\section{Screw-pine Leaves}

Screw pine tree is a palm like, ever green tree, with long, thick leaves that grow on the banks of ponds, and lakes and are used to polish toys after application of lac, to make the toys bright and lustrous.

\section{TOY MAKING TOOLS}

Cutting tools are used to scrape uniform, thin layers of wood to create desired shape. The toy is sanded with sandpaper while it is still turning, until the surface is smooth and uniform.

Measuring equipment such as compass, angles, planes and Vernier calipers are used by the artisans as shown in figure 7. Files and chisels are used for filing.

Power lathes are usually used in small factories, where there is electricity, and are not commonly used in homes of free-lance artisans, as shown in figure 8. An electric power lathe has a headstock, with a revolving axle attached to pulleys. The production time decreases considerably on the power lathe as artisans can use both hands to operate cutting tools. Overhead belt drivers that are driven by a small electrical motor, and one end of the belt drive converts the vertical motion into horizontal circular motion. After the product is cut, the product is lacquered.
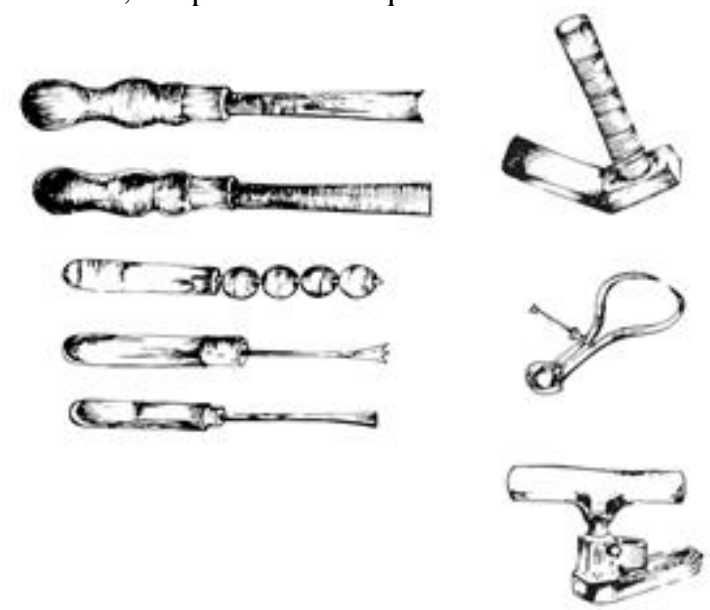

Figure 7 Tools used in toy making
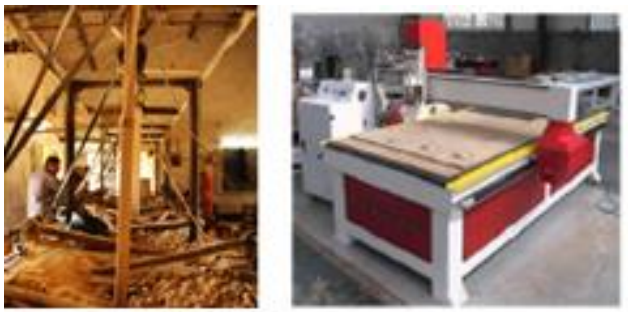

Figure 8 Electric lathe, and CNC machine

\section{TOY MAKING PROCESS}

The toy making process consists of 6 main steps. Artisans are trained in seasoning, and lac preparation for an average period of three months.

They are trained to carve simple forms of toys using hand held tools, before they are trained to operate machines such as electric lathe.

In some traditional workshops, artisans specialize in carving certain types of toys.

The steps involved in the process are listed below.

Step 1: Procuring raw material: The raw materials are sourced and prepared on site.

Step 2: Wood seasoning: Wood is seasoned close to wood workshops. Logs are cut into billets, and seasoned until they are dry and can be turned on the lathe

Step 3: Lac preparation: Lac sticks are made by mixing lac with lithophone.

Step 4: Shaping: Toys are shaped using hand tools and lathe. Step 5: Lacquering: Lac is applied while the toy is on the lathe. The resulting friction causes lac to bind to the surface of the toy.

Step 6: Polishing: The toys are polished using screw pine leaves to make the surface smooth and lustrous.

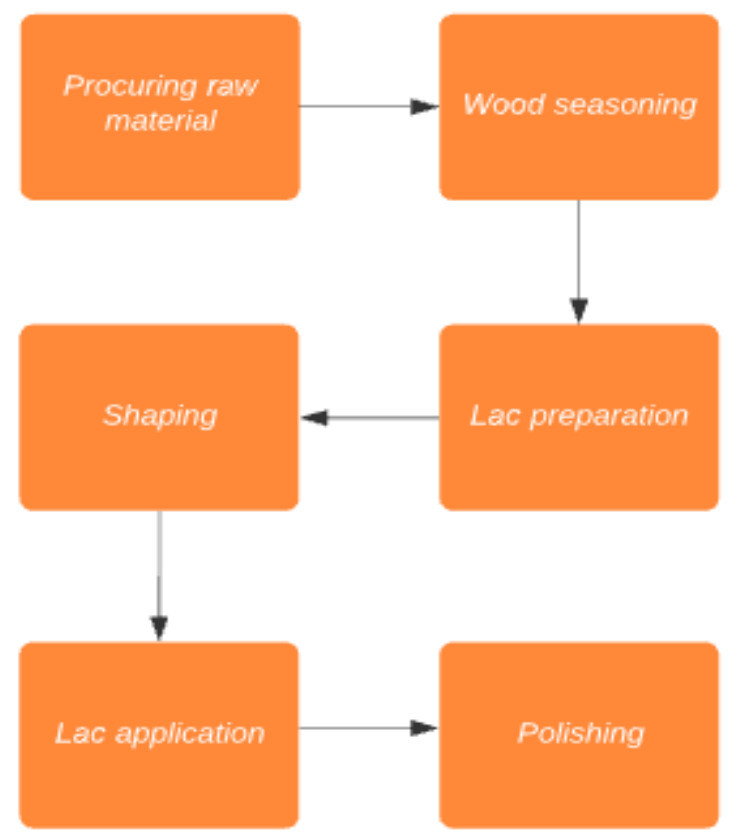

Figure 9 Flow Chart Showing Toy Making Process

\section{A. Types of Toy Making Workshops}

a. A number of family members, including women and children may produce lacquerware. The artisans in household units either hire power lathes at the KHDC center or own hand lathes. Most of them are self-employed, marketing their goods at outlets such as retail shops or export units of the KHDC.

b. Small scale enterprises are set-up in artisans' houses with a minimum of 4 to 10 lathes. Hired laborers work on a piece rate basis. These enterprises sell their products directly to exporters, work through agents or through the KHDC.

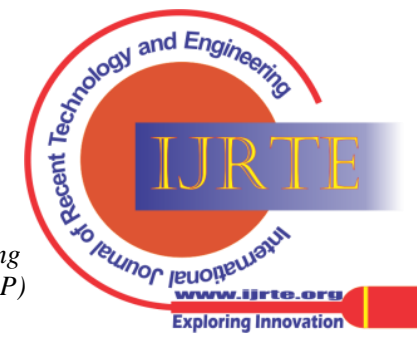




\section{A Study of Traditional Toy Making in Channapatna, and Proposal of an Artisan Village}

c. Medium scale industries are generally established or owned by exporters in Channapatna. These have a minimum turnover of 3 lakhs and employ artisans on wages or piece rate basis. There are a few exporters in Bangalore who enter quantity or given item and quantity. Specifications describing the desired products are given by the exporter with a strict focus on quality.

The packaging required for export also creates employment. Most of the containers are produced in the household or by small scale enterprises that employ both men and women. Toys that are to be exported are made according to buyer specifications. A pre-production sample is sent to the buyer for checking the quality. After the necessary quality checks are made, orders are bulk produced and exported. Packaging of toys is usually out sourced. Total annual lacquerware production for the Channapatna area is estimated to be around Rs 3 crores. Seventy percent of total production is exported. Ninety nine percent of this is handled by a few private exporters who, as a result, control prices and make most of the profit. Two percent goes to the government of Karnataka State Handicrafts Development Corporation (KHDC). Presumably the remaining $28 \%$ of the production goes to the local market. (http://www.fao.org, 2016)

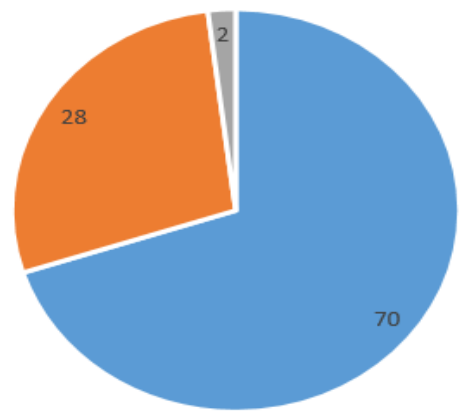

- Exports - Local stores = Govt. stores

\section{Figure 10 Pie chart showing percentage of product distribution channels}

\section{PROBLEMS FACED BY ARTISANS}

Power Disruption: The frequent and unscheduled disruption in power supply affects the productivity, as the lathe turning process is dependent on electricity. Many areas experience power cuts lasting 4-5 hours, forcing artisans to spend extra time to meet targets. Lack of light and ventilation: Most workshops are ill-ventilated as shown in figure 11. In most small units, there is lack of adequate facilities for the artisans such as sufficient number of wash rooms, lockers, and staff lounge. Women prefer taking up other occupations, as the work place does not have infrastructure such as wash rooms, and the lack of light in most workshops makes the workers feel uncomfortable. Hygiene: The floor of the manufacturing unit is not cleaned frequently forcing the artisans to work amidst accumulated sawdust. No safety gear is provided to the artisans who cut wood. The sawdust is collected and sold to incense stick factories. Discarded pieces of wood are stacked, and used as firewood. The craft is eco-friendly as the bi-products are also used and not disposed in landfills. However, as most factories and home manufacturing units lack any sort of dust collector machines, the workers are forced to work amidst fallen sawdust. into contracts with artisans for the production of a desired

Artisan resonance rate: One of the main reasons for the decline of toy making is the high resonance rate. Due to poor pay, working conditions, and lack of job security artisans are shifting to better paying jobs. Younger artisans are unwilling to work on the craft form due to the low pay scale, and the poor working conditions. (Varrier, 2021)

Waste of raw material: Ivory wood loses its malleability when exposed to moisture. Most workshops store wood in semi-open areas, as shown in figure 12 and cover it when it rains. Heavy rains can drench the stored wood, leading to wastage. There is no refrigeration present in most manufacturing units. This causes lac to melt, especially in the summer months when average temperatures can reach 35 degree Celsius. Traditionally indigo dye was used to outline and draw finer details of the toys. Due to increasing cost, and decreasing availability, the use of indigo has reduced.

Skill oriented issues: There is no fixed duration to train an artisan, or standard operating procedure to train artisans. This affects productivity.
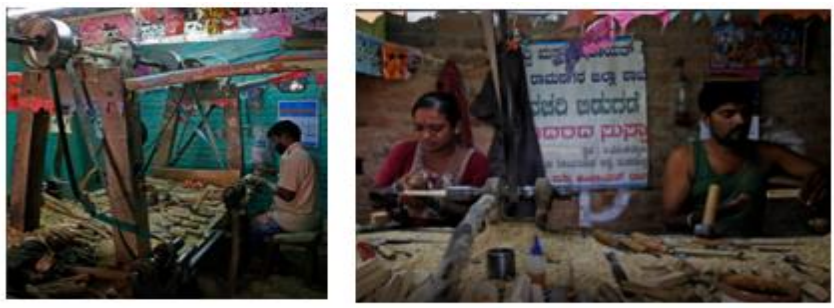

Figure 11 Most workspaces lack light and ventilation
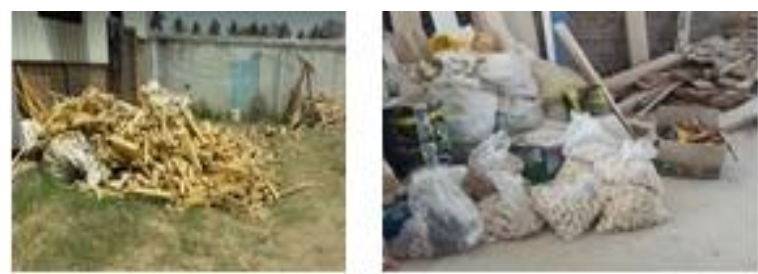

Figure 12 Wood storage area

Imitation of toys: Fake counterfeits that are neither authentic nor eco-friendly threaten the craft form. Due to lack of awareness of the product and craft, customers believe counterfeits to be original. (Masoodi, 2018) Lack of awareness: The craft is not well known outside South India, and this affects the sale of toys at a national level. The USP of the toys is that they are eco-friendly, child safe and non-toxic. Health issues: The ivory wood tree is a medicinal tree, and the artisans do not suffer from any adverse respiratory effects due to working with the wood. However general accessibility to health care is limited. There is one government hospital in the precinct, however artisans prefer to seek treatment privately, due to limited facilities. (Shrivatsava, 2016)

\section{INFERENCES}

Architecture can play an important role in improving the working and living conditions of the artisans, and this in turn will boost productivity, and improve the sales of traditional wooden toys. In interviews, one artisan said, "I love this work, even though it doesn't pay that well.

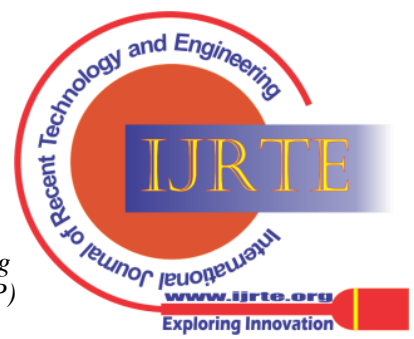


And all I want is to do good work . . . and to have the opportunity to keep making more and More." When I asked whether they ever got bored, an artisan said, "You don't get bored by working on these kind of things, because every time you are making new and different things."

Another artisan spoke more generally: "The end is not making money. It's the deep satisfaction this gives you." (Ranganathan, n.d.)

Traditionally, the artisans did not make detailed sketches of their products prior to crafting them; their creativity depended on the ability to make real-time modifications.

In interviews, artisans said that they did not oppose technology in general; they objected only to technology that impeded their relationship with their work. Several artisans independently illustrated this point by recounting that the electric lathe - in common use in Channapatna - had been introduced by Japanese visitors a few decades ago. Prior to their visit, artisans had used hand lathes. However, upon seeing the potential of the electric lathe to promote efficiency and advance their craft, they enthusiastically adopted the new technology.

If a new technology allows me to earn more without interfering with my work, I'd be the first one to adopt it." Any proposed architectural intervention should not affect the working environment that the artisans are used to.

Based on the working conditions and need of artisans, this paper proposes to set up an artisan village in Channapatna, in a region segregated for mixed use development.

Some of the features of the proposed artisan village are:

- Most workshops have a standard layout with barely enough room for machinery and circulation. Basic stools for the artisans are present, with no spill out spaces, or storage spaces. The workshops can be redesigned such that they are lit by passive day-lighting techniques that will help create ergonomic working conditions for artisans and also provide more opportunities for women artisans.

- Spaces for staff such as adequate washrooms, locker rooms, staff lounge and pantry will make the workshops more user friendly and draw in more number of artisans.

- Spaces for proper storage, processing of raw material will help reduce wastage of raw material, and improve productivity. Naturally lit wood storage rooms, and partially shaded wood drying area will help reduce wastage of wood due to bad weather, and lead to increased production.

- Screw pine leaves and lac can be grown locally to reduce transportation costs, and improve availability.

- Designing packaging units, which make packaging on site with eco-friendly materials such as industrial hemp, will help improve the reach of the toys, and reduce dependency on middle-men.

- Designing a training center will help streamline the toy making process, and help preserve the craft form.

- Designing on-site accommodation units for single artisans, and those who live with their families.

- Designing retail areas; such as shops, stalls, and kiosks to provide a place for toy makers to sell their wares, within the artisan village.

- Designing visitor areas such as a display center, and cafeteria to draw in visitors.

\section{CONCLUSION}

The proposed architectural solutions will help revive the traditional craft form, and improve the reach, and sales of the toys. A movement towards the conservation and revitalization of toy making in India can be achieved on a smaller level to re-vitalize a craft which is child-safe, and eco-friendly.

\section{REFERENCES}

1. census.gov.in. (2021, May 5). Retrieved from http://www.census.gov.in

2. http://www.fao.org. (2016). Retrieved from http://www.fao.org/3/x5859e/x5859e04.htm

3. https://www.reportlinker.com/p03812874/Toys-Market-in-India.html. (2021). Retrieved from https://www.reportlinker.com/p03812874/Toys-Market-in-India.html

4. Masoodi, A. (2018). The toy makers of Channapatna. Retrieved from livemint.com:

https://www.livemint.com/Industry/ZAyV11M3KAT267yj0txQWO/Th e-toymaker-of-Channapatna.html

5. Ranganathan. (n.d.). Retrieved from http://web.stanford.edu/ arunar/docs/9-Ranganathan_IdentifiedWorker .pdf

6. Shrivatsava, I. (2016, January). https://issuu.com/ishitasrivastava18/docs/clusture_new_pages_final. Retrieved from https://issuu.com/ishitasrivastava18/docs/clusture_new_pages_final

7. Varrier, M. (2021, May). Tragedy of Channapatna, the land of wooden toys in India. Retrieved from newsminute.com: https://www.thenewsminute.com/article/tragedy-channapatna-land-woo den-toys-india

8. www.grandviewresearch.com. (2021, August 31). Retrieved from https://www.grandviewresearch.com/industry-analysis/construction-toy s-market

\section{AUTHOR PROFILE}

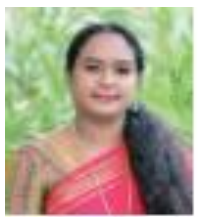

Ar. Uma S.M received the Bachelor of Architecture degree in 2011, M.Tech URP degree in Urban and Regional Planning in 2014 and presently pursuing Ph.D degree in Urban and Regional Planning from the University of Mysore, Mysore. She is working as Assistant Professor in the department of Architecture at School of Planning and Architecture, University of Mysore, Mysore. Her research interests to include Architecture and Urban Planning.

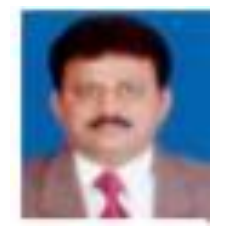

Dr. B. Shankar, received the B.E. degree in Civil Engineering in 1984, M.UR.P 1989 and Ph. D in Urban and Regional Planning from the University of Mysore, Mysore. He is working as Reader in Urban and Regional Planning at the Institute of Development Studies, University of Mysore from July 2007. He has 20 years of experience in the field of urban and regional planning. His current interest includes heritage conservation, planning legislation, governance and management.

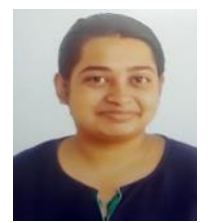

Aparna Agaram Krishnan is a final year student set to complete her Bachelor in Architecture (B.Arch.) degree in 2021 from School of Planning and Architecture, University of Mysore. Her research interests include architectural design, heritage, conservation, and community planning.

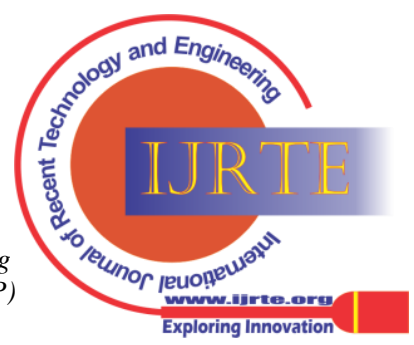

